\title{
A Case of Severe Hyponatremia Secondary to Pituitary Macroad- enoma with Covid-19 Infection, Endocrinological Responses
}

\author{
José Carlos de la Flor Merino, $M^{1^{*}}{ }^{(D)}$, Laura Mola Reyes, $M D^{2}$ (D), Francisco Valga Amado, $M D^{3}$ (D), \\ Alexander Marshall ${ }^{4}$ iD and Miguel Rodeles del Pozo, MD ${ }^{5}$
}

\author{
${ }^{1}$ Department of Nephrology, Central Defense Gomez Ulla Hospital, Spain \\ ${ }^{2}$ Department of Endocrinology, Central Defense Gomez Ulla Hospital, Spain \\ ${ }^{3}$ Department of Nephrology, Doctor Negrín University Hospital, Spain \\ ${ }^{4}$ Department of Cardiology, Central Defense Gomez Ulla Hospital, Spain \\ ${ }^{5}$ Department of Nephrology, Chief of Nephrology Service at Central Defense Gomez Ulla Hospital, Spain
}

*Corresponding author: José Carlos De La Flor Merino, MD, Department of Nephrology, Central defense Gomez Ulla Hospital, Madrid, Spain

\begin{abstract}
SARS-CoV-2 disease (COVID-19) has dramatically increased since March 2020. There is insufficient data to establish the risk of acquiring the hyponatremia in patient with COVID-19 infection. We report here the clinical features and therapeutic course of the severe hyponatremia secondary to pituitary macroadenoma with confirmed COVID-19 pneumonia. This is a 59-year-old man without renal disease, who developed severe hyponatremia, hardly explained by the emetic episode and/or diuretic treatment with thiazides. We know that hyponatremia occurs in patients with hypopituitarism, but infrequently as first presenting feature of a pituitary tumor in the context of a respiratory infection by COVID-19, which has probably exacerbated its presentation. We conclude, that in our case, in addition to the finding of a non-functioning pituitary macroadenoma that determines a cortisol deficiency, we consider that COVID-19 infection could have played a role in the severity of the symptoms of hyponatremia.
\end{abstract}

\section{Keywords}

Hyponatremia, Pituitary macroadenoma, SARS-CoV-2, COVID-19

\section{Introduction}

Hyponatremia is the most common electrolyte disorder with prevalence as high as $30 \%$ in inpatient settings [1]. While hyponatremia is known to occur in patients with hypopituitarism, severe hyponatremia oc- curring as the presenting feature of a pituitary tumor is very rare [2], and even more so in the context of a patient with COVID-19 infection, caused by severe acute respiratory syndrome coronavirus 2 (SARS-CoV-2) [3,4], which has probably exacerbated its presentation.

\section{Case Presentation}

A 59-year-old man with a history of controlled arterial hypertension with the combination of angiotensin-converting enzyme inhibitors and hydrochlorothiazide that had been suspended 4 days before admission. He consulted for 10-day history of dry cough, slight respiratory distress, fever, and poor general condition. Three days before, abdominal pain, nausea and vomiting were added ( 10 episodes/day), and 24 hours before, headache and drowsiness. The examination revealed blood pressure $140 / 90 \mathrm{mmHg}$, respiratory rate of 26 breaths/min, and oxygen saturation of $89-90 \%$ while breathing room air, with pulmonary rales but without peripheral edema, volume of urine output $60 \mathrm{ml} /$ hour and confusion, bradypsychia, and mild clinical signs of dehydration of the skin and mucosa. The analysis highlighted severe hyponatremia (102 $\mathrm{mEq} / \mathrm{L})$ in the $a b$ sence of azotemia, the rest of the analysis in Table 1. In addition to C-reactive protein $5.05 \mathrm{mg} / \mathrm{dl}(0.02-0.05$ $\mathrm{mg} / \mathrm{dl}$ ), ferritin $252 \mathrm{ng} / \mathrm{ml}$ (30-400 ng/ml), D-dimer 174 
Table 1: Laboratory values.

\begin{tabular}{|c|c|c|c|c|}
\hline & On admission & Fifth day & Eighth day & Reference range \\
\hline Sodium serum (mEql/L) & 102 & 125 & 139 & $135-145$ \\
\hline Potassium serum (mEq/L) & 4.3 & 4.1 & 4.1 & $3.5-4.5$ \\
\hline Chloride serum (mEq/L) & 71 & 91 & 99 & $98-110$ \\
\hline Bicarbonate serum (mEq/l) & 20.6 & 22.7 & 28 & $22-28$ \\
\hline Creatine serum $(\mathrm{mg} / \mathrm{dl})$ & 0.6 & 0.8 & 0.9 & $0.6-1.2$ \\
\hline Osmolarity serum calculed (mOsm/Kg) & 215 & 267 & 290 & $270-298$ \\
\hline Urea serum (mg/dl) & 21 & 18 & 31 & $17-60$ \\
\hline Uric acid, serum (mg/dl) & 2.4 & 2.8 & 2.9 & $3.4-7$ \\
\hline Osmolarity, urine (mOsm/Kg) & 990 & 660 & 330 & $80-1200$ \\
\hline Sodium urine $(\mathrm{mEq} / \mathrm{L})$ & 157 & 82 & 52 & $20-200$ \\
\hline Cortisol ( $\mu \mathrm{g} / \mathrm{dl})$ & NA & 3.1 & NA & 4.8-19.5 \\
\hline Adrenocorticotropic Hormone (ACTH) (pg/ml) & NA & 4.6 & NA & $7-60$ \\
\hline Prolactin (ng/ml) & NA & 8.7 & NA & $4-15.2$ \\
\hline Folicule-Stimulating Hormone (FSH) $(\mathrm{mU} / \mathrm{mL})$ & NA & 2.5 & NA & 1.5 a 12.4 \\
\hline Luteinizing Hormone $(\mathrm{LH})(\mathrm{mU} / \mathrm{mL})$ & NA & 0.2 & NA & $1.7-8.6$ \\
\hline Growth hormone (ng/ml) & NA & 0.06 & NA & $0.05-3$ \\
\hline Insulin-like Growth Factor 1 (IGF-1) (ng/ml) & NA & 36.6 & NA & $36-200$ \\
\hline Testosterona (ng/ml) & NA & 0.03 & NA & $1.93-7.4$ \\
\hline Thyroid-Stimulating Hormone (TSH) $(\mu \mathrm{U} / \mathrm{ml})$ & NA & 1.6 & NA & $0,35-4$ \\
\hline Thyroxine (T4) (ng/dL) & NA & 0.9 & NA & $0.75-1.8$ \\
\hline
\end{tabular}

NA: Not applicable.

$\mathrm{ng} / \mathrm{ml}(0-500 \mathrm{ng} / \mathrm{ml})$ and lymphocytes $1.35 \times 103 / \mathrm{ul}$. Chest- X-ray showed bilateral alveolar-interstitial pattern. PCR for SARS-CoV-2 was positive.

Given the presence of a severe acute hyponatremia with neurological symptoms, was treated with bowling i.v. $100 \mathrm{ml}$ of $3 \%$ hypertonic solution, up to 3 times with periods of 10 minutes between boluses, stopping them on cessation of severe symptoms, according to well established guidelines [5]. Subsequently, 2 liters per day of sodium chloride $(0.9 \%)$ solution were administered. The next day the natremia was $111 \mathrm{mEq} / \mathrm{L}$ and the third day serum sodium was 118 , so a Syndrome of Inappropriate Antidiuretic Hormone Secretion (SIADH) was initially raised and treatment with urea $15 \mathrm{grs}$ was started twice a day, fluid restriction and oral intake of salt. On the fifth day the natremia values $>125 \mathrm{mEq} / \mathrm{L}$ have not been reached. Our patient developed a mild pneumonia without the need for oxygen at high flows nor mechanical ventilation according of technical document of clinical management of COVID-19 of the hospital care (Spain-Health-System) and was treated with azithromycin, hydroxychloroquine, lopinavir/ritonavir and received Low Molecular Weight Heparin (LMWH) on a prophylactic dose. Dexamethasone was not used.

Hormonal evaluation showed low levels of Adrenocorticotropic Hormone (ACTH) and cortisol, the rest of the study in Table 1. Magnetic Resonance Imaging (MRI) revealed a pituitary macroadenoma, with signs of intralesional hemorrhage. On the sixth day, actcortin
$100 \mathrm{mg}$ every $12 \mathrm{~h}$ was prescribed, and thereafter 100 $\mathrm{mg}$ over $24 \mathrm{hr}$ by continuous infusion. The following three days, the natremia was $139 \mathrm{mEq} / \mathrm{L}$. The campimetry test detected the presence of amaurosis of the left eye and temporal hemianopia of the right eye. The final diagnosis was severe euvolemic hyponatremia due to secondary adrenal insufficiency as a manifestation of Hypopituitarism (HPT) secondary to pituitary macroadenoma and apoplexy in a patient with COVID-19 infection. Finally, the endoscopic transsphenoidal surgery was performed. During the postoperative period, the patient presents a polyuria that persists after discharge; it is probably related to post-surgical diabetes insipidus transitory, which resolves in the following weeks. During the follow-up after hospital discharge, the natremia remained normal.

\section{Discussion}

The association between the involvement of the hypothalamo-pituitary-adrenal axis and a type of coronavirus (SARS), was first reported by Leow, et al. in 2005 [6]. Sixty-one survivors of SARS were evaluated at 3 months post-recovery and thereafter periodically. Forty percent of patients had evidence of central hypocortisolism, the majority of which (62.5\%) resolved within a year. The authors had proposed the possibility of a reversible hypophysitis or a direct hypothalamic damage that could have led to a state of hypothalamo-pituitary dysfunction.

The association of hyponatremia and COVID-19 in- 
fection has been described in recent studies, although the possible underlying pathophysiological mechanisms are not known currently, we do not have any such data on cortisol dynamics in patients with COVID-19; however, considering the high frequency of neurological symptoms, one can assume that SARS-CoV-2 may affect the hypothalamus-pituitary as well $[1,2,7,8]$.

In our clinical case, the analytical parameters were initially interpreted as SIADH, which was finally ruled out after the finding of hypocortisolism. Hyponatremia is a direct consequence of glucocorticoid deficiency and is related to inappropriate antidiuresis resulting from non-suppressible arginine vasopressin release (despite hypoosmolality) and, probably, to a direct renal water excretion defect, both being consequences of cortisol deficiency. Other factors also probably contribute to hyponatremia in these patients. By irritating hypothalamus, pituitary apoplexy can produce syndrome of inappropriate antidiuretic hormone with hyponatremia; in that setting, serum bicarbonate measurement is useful for differentiating syndrome of inappropriate antidiuretic hormone and corticotropin deficiency as it is lower in this latter condition [9]. Hypothyroidism secondary to thyrotropic deficiency may also contribute to hyponatremia, however our patient did not present these alterations. Nausea and vomiting (related to both ACTH/ cortisol and GH/IGF-1 deficiency) are non-osmotic stimuli of arginine vasopressin release [10]. At the same time, nausea and vomiting are symptoms that could be derived from both adrenal insufficiency and hyponatremia [5].

We conclude that in patients diagnosed with hyponatremia, adrenal insufficiency must be ruled out because its treatment rapidly corrects hyponatremia, while its omission can have serious consequences. In our case, in addition to the finding of a non-functioning pituitary macroadenoma that determines a cortisol deficiency; COVID-19 infection could have contributed to the hyponatremia picture through the mentioned mechanisms. Consequently, endocrinologists should be aware of central hypercortisolism in survivors of COVID-19.

\section{References}

1. Upadhyay A, Jaber BL, Madias NE (2006) Incidence and Prevalence of Hyponatremia. Am J Med 119: 30-35.

2. Lin SH, Hung YH, Lin YF (2002) Severe hyponatremia as the presenting feature of clinically non-functional pituitary adenoma with hypopituitarism. Clin Nephrol 57: 85-88.

3. Huang C, Wang Y, Li X, Ren L, Zhao J, et al. (2020) Clinical features of patients infected with 2019 novel coronavirus in Wuhan, China. Lancet 395: 497-506.

4. Guan W, Ni Z, Hu Y, Liang W, Ou C, et al. (2020) Clinical characteristics of coronavirus disease 2019 in China. N Engl J Med 382: 1708-1720.

5. Verbalis JG, Goldsmith SR, Greenberg A, Korzelius C, Schrier RW, et al. (2013) Diagnosis, evaluation, and treatment of hyponatremia: Expert panel recommendations. American Journal of Medicine 126: 1-42.

6. Leow MKS, Kwek DSK, Ng AWK, Ong KC, Kaw GJL, et al. (2005) Hypocortisolism in survivors of severe acute respiratory syndrome (SARS). Clin Endocrinol 63: 197-202.

7. Gu J, Gong E, Zhang B, Zheng J, Gao Z, et al. (2005) Multiple organ infection and the pathogenesis of SARS. J Exp Med 202: 415-424.

8. Pal R, Banerjee M (2020) COVID-19 and the endocrine system: Exploring the unexplored. J Endocrinol Invest 2: $1-5$.

9. Briet C, Salenave S, Bonneville JF, Laws ER, Chanson P (2015) Pituitary apoplexy. Endocrine Reviews 36: 622-645.

10. Vicente A, Lecumberri B, Gálvez MÁ (2013) Clinical practice guideline for the diagnosis and treatment of pituitary apoplexy. Endocrinol y Nutr 60: 582. 